\title{
A 10-Item Frailty Index Based on a Comprehensive Geriatric Assessment (FI-CGA-10) in Older Adults with Cancer: Development and Construct Validation
}

\author{
Tomohiro F. Nishijima id, a,b,e Mototsugu Shimokawa, ${ }^{\text {c,f }}$ Taito Esaki, ${ }^{b}$ Masaru Morita, ${ }^{d}$ Yasushi Toh, ${ }^{d}$ Hyman B. Muss ${ }^{e}$ \\ ${ }^{a}$ Geriatric Oncology Service, ${ }^{a}$ Gastrointestinal and Medical Oncology, ${ }^{a}$ Cancer Biostatistics Laboratory, and ${ }^{a}$ Gastroenterological Surgery, \\ National Hospital Organization (NHO) Kyushu Cancer Center, Fukuoka, Japan; ${ }^{\circledR}$ Department of Medicine, Division of Oncology,

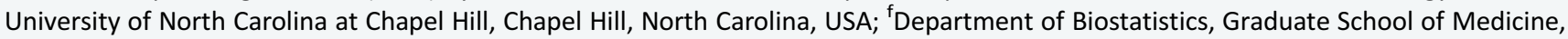 \\ Yamaguchi University, Yamaguchi, Japan \\ Disclosures of potential conflicts of interest may be found at the end of this article.
}

Key Words. Frailty • Comprehensive geriatric assessment • Construct validation •

Frailty index • Older adults with cancer

\section{Abstract}

Background. A frailty index (FI) based on domain-level deficits identified through a comprehensive geriatric assessment (CGA) has been previously developed and validated in general geriatric patients. Our objectives were to construct an FI-CGA and to assess its construct validity in the geriatric oncology setting.

Methods. Five hundred forty consecutive Japanese patients with cancer who underwent a CGA on a geriatric oncology service were included (median age 80 years, range 6696 years). We developed a 10-item frailty index based on deficits in 10 domains (FI-CGA-10): cognition, mood, communication, mobility, balance, nutrition, basic and instrumental activities of daily living, social support, and comorbidity. Deficits in each domain were scored as 0 (no problem), 0.5 (minor problem), and 1.0 (major problem). Scores were calculated by dividing the sum of the scores for each domain by 10 and then categorized as fit $(<0.2)$, pre-frail $(0.2-0.35)$, and frail $(>0.35)$. Construct validity was tested by correlating the FI-CGA-10 with other established frailty measures.

Results. FI-CGA-10 was well approximated by the gamma distribution. Overall, $20 \%$ of patients were fit, $41 \%$ were pre-frail, and $39 \%$ were frail. FI-CGA-10 was correlated with Canadian Study of Health and Aging (CSHA) Clinical Frailty Scale $(r=0.83)$, CSHA rules-based frailty definition $(r=0.67)$, and CSHA Function Score $(r=0.77)$. Increasing levels of frailty were significantly associated with functional and cognitive impairments, high comorbidity burden, poor self-rated health, and low estimated survival probabilities.

Conclusion. The FI-CGA-10 is a user-friendly and constructvalidated measure for quantifying frailty from a CGA. The Oncologist 2021;26:e1751-e1760

Implications for Practice: This article describes the construction of a user-friendly 10-item frailty index based on a comprehensive geriatric assessment (FI-CGA-10) for older adults with cancer: cognition, mood, communication, mobility, balance, nutrition, basic and instrumental activities of daily living, social support, and comorbidity. The FI-CGA-10 simplifies the original FI-CGA used in the general geriatric setting while maintaining its content validity. The index's construct validity was demonstrated in a cohort of older adults with various cancer types. The advantage of the FI-CGA-10 is that a frailty score can be calculated more readily and interpreted in a more clinically sensible manner than the original FI-CGA.

\section{INTRODUCTION}

Frailty is a multidimensional syndrome characterized by loss of reserve and resistance to stressors, which increases an individual's vulnerability to poor health outcomes [1]. Studies of older adults with cancer have shown that frailty is

Correspondence: Tomohiro F. Nishijima, M.D., 3 Chome-1-1 Notame, Minami Ward, Fukuoka, Fukuoka Prefecture 811-1395, Japan. Telephone: 81-92-541-3231; e-mail: nishijima.tomohiro.zg@mail.hosp.go.jp Received March 18, 2021; accepted for publication June 18, 2021; published Online First on July 10, 2021. http://dx.doi.org/10.1002/onco.13894

No part of this article may be reproduced, stored, or transmitted in any form or for any means without the prior permission in writing from the copyright holder. For information on purchasing reprints contact commercialreprints@wiley.com. For permission information contact permissions@wiley.com. 
associated with chemotherapy intolerance, postoperative complications, and death $[2,3]$. Although there is no consensus on how to measure frailty, the two most widely accepted approaches are the phenotype model and the cumulative deficit model [4]. The phenotype model establishes a frailty phenotype using five variables: unintentional weight loss, weak grip strength, self-reported exhaustion, slow gait speed, and low physical activity [5]. The cumulative deficit model forms the basis of a frailty index (FI) based on a wide variety of age-related deficits [6].

Based on these models, many tools have been developed to measure frailty; however, there is currently no gold standard. Sutton et al. performed a systematic review to evaluate the psychometric properties of multicomponent frailty assessment tools specifically designed to measure frailty in older adults [7]. Of 38 tools evaluated in the review, one of only two tools that had acceptable evidence of reliability and validity was the Frailty IndexComprehensive Geriatric Assessment (FI-CGA).

FI-CGA was constructed by Jones and Rockwood based on domain-level deficits in a standardized comprehensive geriatric assessment (CGA) [8, 9]. Comprehensive Geriatric Assessment is defined as "a multidimensional, interdisciplinary, diagnostic process to identify care needs, plan care, and improve outcomes of frail older people" [10]. The FICGA comprised of assessments in 10 impairment domains (cognition, mood, communication, mobility, balance, bowels, bladder, nutrition, daily activities, and social) and a single comorbidity domain. Impairments within each domain are categorized into a three-level rating system: no problem, a minor problem, or a major problem. The FI-CGA score is calculated by counting the number of domain-level impairments and normalizing it to a score between 0 and 1. In a secondary analysis of data from the Canadian Study of Health and Aging-2 (CSHA-2), the FI-CGA correlated highly with the original version of the previously validated frailty index (Pearson's $r=0.76$ ) [9]. Higher FI-CGA score was associated with higher risk of death and institutionalization. For each increment in frailty, the adjusted hazard ratio was 1.23 (95\% confidence interval [Cl], 1.18-1.29) and $1.20(95 \% \mathrm{Cl}, 1.10-1.32)$ for death and institutionalization, respectively [9]. This FI-CGA domain-based approach to frailty index has not been tested in older adults with cancer. The objectives of this study were to construct an easy-touse FI-CGA applicable in the geriatric oncology setting and to investigate its construct validity.

\section{Materials ANd Methods}

\section{Patients}

The geriatric oncology service at the National Hospital Organization Kyushu Cancer Center (NKCC) in Japan was launched in September 2018. Nurses administered the G8, a geriatric screening tool, for all new patients aged 75 years and older at their initial clinic visit to the NKCC [11]. A referral for CGA conducted at the geriatric oncology service was made at the discretion of the treating physician based on their clinical judgment and the G8 score, where available. A geriatric oncologist (T.F.N.) completed the CGA, which included four major elements, namely, physical health, functional status, psychological health, and socioenvironmental parameters [12-14]. The assessment was performed not only with the patient but also whenever possible with their caregiver(s). The referring physician was provided with a summary of the CGA findings and recommendations for cancer treatment and targeted interventions to address identified vulnerabilities. In addition, we recorded baseline sociodemographic data, Eastern Cooperative Oncology Group performance status (ECOG PS), tumor and treatment characteristics, and pretreatment laboratory data [15]. The data were prospectively collected into an electronic database. Consecutive patients who had undergone CGA at the geriatric oncology service between September 2018 and October 2020 were included in this cohort. These assessments were conducted as a part of routine clinical practice. Patients provided written informed consent for the collection of clinical data and for the use of the data for research. The study was approved by the Institutional Review Board.

\section{Constructing the FI-CGA-10}

We constructed a 10-item FI-CGA (FI-CGA-10) based on a modification of the original FI-CGA. The original FI-CGA consists of an impairment index and a comorbidity index [9]. The impairment index consists of 10 domains: cognition, mood, communication, mobility, balance, bowels, bladder, nutrition, daily activities, and social support. Impairments in each domain are scored as 0 (no problem), 0.5 (a minor problem), and 1.0 (a major problem). The impairment index score ranges from 0 to 10 . The comorbidity index is assessed using the Cumulative Illness Rating Scale, and its score is standardized into a range of 0 to 4 [16]. The FI-CGA score is calculated by dividing the sum of the impairment and comorbidity index scores by 14 .

In the FI-CGA-10, we reclassified the daily activities, bladder, and bowel domains and simplified the assessment of comorbidity. First, we divided the daily activities domain in the original FI-CGA, which includes both activities of daily living (ADLs) and instrumental activities of daily living (IADLs), into two independent domains: ADL and IADL. We then incorporated the bladder and bowel domains into the ADL domain by defining the ADL impairment level 0.5 as "bladder and/or bowel incontinence." Second, we treated comorbidity as one of the domains and scored it in the same way as the other domains (i.e., three levels of impairment: $0,0.5$, and 1.0 ). With these changes, we had a total of 10 domains including comorbidity in the FI-CGA-10.

Table 1 describes the measures and the scoring definitions for the 10 domains. We evaluated each domain with tools commonly used in geriatric oncology and defined the impairment level of each domain based on the original FICGA and relevant literature. Cognitive status was initially screened using the Mini-Cog [17]. For patients with a MiniCog score $\leq 4$, the Montreal Cognitive Assessment (MOCA) was performed [18]. This threshold was chosen to increase sensitivity to screen for cognitive impairment [19]. For patients with a history of dementia, the Mini-Mental State Exam, instead of the MOCA, was performed [20]. Emotional status was initially assessed using the Patient Health 
Table 1. FI-CGA-10 scoring system for each domain based on severity of the problem

\begin{tabular}{|c|c|c|c|c|c|}
\hline \multirow[b]{2}{*}{10 CGA domains } & \multicolumn{3}{|c|}{ Scoring system } & \multirow{2}{*}{$\begin{array}{l}\text { No. } \\
\text { of } \\
\text { items }\end{array}$} & \multirow{2}{*}{$\begin{array}{l}\text { Relevant } \\
\text { literature } \\
\text { for } \\
\text { scoring }\end{array}$} \\
\hline & 0 (no problem) & 0.5 (minor problem) & 1.0 (major problem) & & \\
\hline 1. Cognition ${ }^{a}$ & No cognitive impairment & $\begin{array}{l}\text { Mild Cognitive } \\
\text { Impairment }\end{array}$ & Dementia & $2^{b}$ & {$[8,9]$} \\
\hline 2. Emotion & $\mathrm{PHQ}-2<3$ or $\mathrm{PHQ}-9<5$ & $5 \leq \mathrm{PHQ}-9<10$ & PHQ-9 $\geq 10$ & $2^{c}$ & {$[22]$} \\
\hline 3. Communication ${ }^{a}$ & $\begin{array}{l}\text { No interference with } \\
\text { activities }\end{array}$ & $\begin{array}{l}\text { Some interference with } \\
\text { activities }\end{array}$ & $\begin{array}{l}\text { Major interference with } \\
\text { activities }\end{array}$ & 4 & {$[35,36]$} \\
\hline 4. Mobility & Gait speed $\geq 1.0 \mathrm{~m} / \mathrm{s}$ & $\begin{array}{l}0.8 \mathrm{~m} / \mathrm{s} \leq \text { Gait speed }<1.0 \\
\mathrm{~m} / \mathrm{s}\end{array}$ & Gait speed $<0.8 \mathrm{~m} / \mathrm{s}$ & 1 & [37] \\
\hline 5. Balance & $\begin{array}{l}\text { No. of falls in past } 6 \\
\text { months }=0\end{array}$ & $\begin{array}{l}\text { No. of falls in past } 6 \\
\text { months }=1\end{array}$ & $\begin{array}{l}\text { No. of falls in past } 6 \\
\text { months } \geq 2\end{array}$ & 1 & {$[9,38]$} \\
\hline 6. Nutrition & $\begin{array}{l}\text { Weight loss in past } 3-6 \\
\text { months }<5 \%\end{array}$ & $\begin{array}{c}5 \% \leq \text { Weight loss in past } \\
3-6 \text { months } \leq 10 \%\end{array}$ & $\begin{array}{l}\text { Weight loss in past 3-6 } \\
\text { months }>10 \%\end{array}$ & 1 & {$[27,28]$} \\
\hline 7. $A D L^{a}$ & OARS ADL $=14$ & $\begin{array}{l}\text { OARS ADL }=12 \text { or } 13 \\
\text { (only due to } \\
\text { incontinence question) }\end{array}$ & $\begin{array}{l}\text { OARS ADL }<14 \text { (including } \\
\text { at least one } \\
\text { impairment other than } \\
\text { incontinence) }\end{array}$ & 7 & [39] \\
\hline 8. $I A D L^{a}$ & OARS IADL $=14$ & OARS IADL $=12$ or 13 & OARS IADL $\leq 11$ & 7 & {$[40,41]$} \\
\hline 9. Social support ${ }^{a}$ & All of the time & Most or Some of the time & $\begin{array}{l}\text { A little or None of the } \\
\text { time }\end{array}$ & 1 & {$[42]$} \\
\hline 10. Comorbidity & $\begin{array}{c}\text { No. of level } 3 \text { or } 4 \\
\text { severity CIRS-G } \\
\text { categories }=0\end{array}$ & $\begin{array}{l}\text { No. of level } 3 \text { or } 4 \\
\text { severity CIRS-G } \\
\text { categories }=1 \text { or } 2\end{array}$ & $\begin{array}{l}\text { No. of level } 3 \text { or } 4 \\
\text { severity CIRS-G } \\
\text { categories } \geq 3\end{array}$ & 14 & {$[43]$} \\
\hline
\end{tabular}

${ }^{\mathrm{a}}$ See supplemental online Appendix for more detailed descriptions of scoring definitions.

${ }^{\mathrm{b}}$ For patients with a Mini-Cog score $\leq 4$, the Montreal Cognitive Assessment (MOCA) was performed. For patients with a history of dementia, the Mini-Mental State Exam (MMSE), instead of the MOCA, was performed. The number of questions for the MOCA and MMSE is 18 and 20 , respectively.

${ }^{c}$ For patients with a PHQ-2 score $\geq 3$, an additional seven questions were asked to perform the PHQ-9.

Abbreviations: ADL, activity of daily living; CIRS-G, Cumulative Illness Rating Scale for Geriatrics; FI-CGA-10, 10-item frailty index based on a comprehensive geriatric assessment; IADL, instrumental activity of daily living; OARS, Older American Resources and Services; PHQ, Patient Health Questionnaire.

Questionnaire-2 (PHQ-2) [21]. For patients with a PHQ-2 score $\geq 3$, the PHQ-9 was performed [22]. Communication was assessed by self-rated hearing and vision status using questions from the Older Americans Resources and Services (OARS) Physical Health Section [23, 24]. Patients were asked to rate their hearing (with a hearing aid if needed) and eyesight (with glasses or contacts) as "excellent," "good," "fair," "poor," or "totally deaf/blind." Patients who rated either their hearing or eyesight as "fair," "poor," or "totally deaf/blind" were asked, "How much does it interfere with your activities?", using the following options: "not at all," "somewhat," or "a great deal." Mobility was assessed by gait speed measured using a 4-m course and a stopwatch [25]. Patients were instructed to walk at their usual pace from a standing start. Assistive devices were allowed if needed. Balance was assessed by number of falls in the past 6 months $[23,26]$. Nutritional status was assessed by percentage of unplanned weight loss in the last 3 to 6 months $[27,28]$. ADLs and IADLs were evaluated using the OARS $A D L$ and IADL subscales, respectively $[24,29]$. One of the OARS ADL items assesses bladder and/or bowel incontinence. Tangible social support was assessed with a question from the Medical Outcomes Study Social Support Survey [30], asking patients if they had "someone to help with daily chores if you were sick" with responses options from 1 (none of the time) to 5 (all of the time). Comorbidity was defined as the sum of conditions that are not related to the index cancer and assessed using the Cumulative Illness Rating Scale for Geriatrics (CIRS-G) [31, 32]. The CIRS-G classifies comorbid conditions by organ systems and grades each condition from level 0 to 4: no problem, mild, moderate, severe, extremely severe. The number of conditions at severity level 3 and 4 was used as a summary score.

The FI-CGA-10 score was calculated by dividing the sum of the scores for each domain by 10 , the total number of domains considered. The score was normalized to the range of 0 to 1 in a similar way as the original Fl. For example, with 3.5 deficits present, the FI-CGA-10 score would be 3.5/ $10=0.35$. The FI-CGA-10 categorized patients into one of the three categories: fit ( 0 to $<0.2)$, pre-frail $(0.2-0.35)$, and frail $(>0.35)$, according to the cutoff points used in the previously developed Fls for older patients with cancer $[33,34]$.

\section{Comparator Variables}

To assess construct validity, we evaluated the correlation between the FI-CGA-10 and other validated frailty measures. These included the Canadian Study of Health and Aging (CSHA) Clinical Frailty Scale (CFS), the CSHA rulesbased frailty definition, and the CSHA Function Score $[39,44]$. The CSHA Clinical Frailty Scale classifies patients into one of seven categories: (1) very fit, (2) well, 
Table 2. Patient and clinical characteristics $(n=540)$

\begin{tabular}{|c|c|}
\hline Characteristic & Patients ( $n=540), n(\%)$ \\
\hline \multicolumn{2}{|l|}{ Age, years } \\
\hline $65-69$ & $9(2)$ \\
\hline $70-74$ & $37(7)$ \\
\hline $75-79$ & $197(36)$ \\
\hline $80-85$ & $185(34)$ \\
\hline $85-90$ & $93(17)$ \\
\hline$\geq 90$ & $19(4)$ \\
\hline \multicolumn{2}{|l|}{ Sex } \\
\hline Male & $328(61)$ \\
\hline Female & $212(39)$ \\
\hline \multicolumn{2}{|l|}{ ECOG PS } \\
\hline 0 & $170(31)$ \\
\hline 1 & $236(44)$ \\
\hline 2 & $84(16)$ \\
\hline $3-4$ & $50(9)$ \\
\hline \multicolumn{2}{|l|}{ Cancer type } \\
\hline Gastrointestinal tract & $200(37)$ \\
\hline Hepatobiliary and pancreatic & $118(22)$ \\
\hline Head and neck & $67(12)$ \\
\hline Hematologic malignancy & $36(7)$ \\
\hline Genitourinary & $32(6)$ \\
\hline Gynecologic & $31(6)$ \\
\hline Lung & $20(4)$ \\
\hline Other & $36(7)$ \\
\hline \multicolumn{2}{|l|}{ Cancer stage } \\
\hline Stage $\mathrm{I}^{\mathrm{a}}$ & $105(19)$ \\
\hline Stage II & $79(15)$ \\
\hline Stage III & $117(22)$ \\
\hline Stage IV & $228(42)$ \\
\hline Not applicable & $11(2)$ \\
\hline \multicolumn{2}{|l|}{ Educational level } \\
\hline Less than high school & $170(31)$ \\
\hline High school graduate & $276(51)$ \\
\hline Some college or above & $94(17)$ \\
\hline \multicolumn{2}{|l|}{ Marital status } \\
\hline Married & $343(64)$ \\
\hline Widowed & $153(28)$ \\
\hline Separated, divorced & $35(6)$ \\
\hline Single & $9(2)$ \\
\hline \multicolumn{2}{|l|}{ Household composition } \\
\hline Lives alone & $102(19)$ \\
\hline Lives with family & $419(78)$ \\
\hline Lives in a long-term care facility & $19(4)$ \\
\hline
\end{tabular}

ancludes one patient with stage 0 disease.

Abbreviation: ECOG PS, Eastern Cooperative Oncology Group performance status.

(3) managing well, (4) vulnerable, (5) mildly frail, (6) moderately frail, and (7) severely frail, using clinical judgment based mainly on assessment comorbidity, function, and

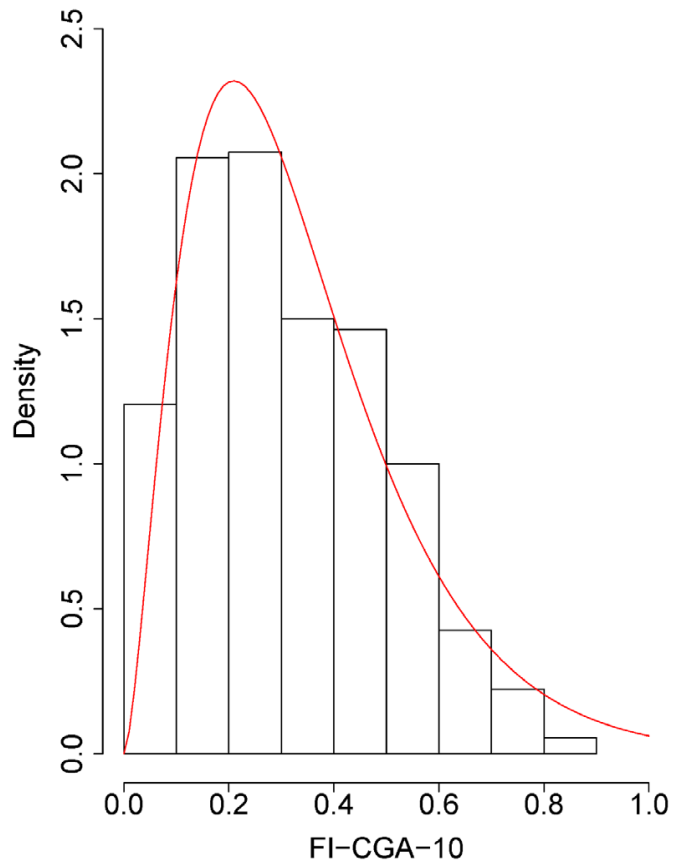

Figure 1. Distribution of the FI-CGA-10 ( $n=540)$. The histogram represents observational data, and the solid curve is a gamma distribution with the parameters of shape (2.64) and scale (0.13).

Abbreviation: FI-CGA-10, 10-item frailty index based on a comprehensive geriatric assessment.

cognitive status [44]. The CSHA rules-based frailty definition classifies patients into one of four levels based on OARS $A D L$ and cognitive status: level 0 (no cognitive or ADL impairment), level 1 (isolated urinary incontinence), level 2 (dependence in one ADL or having a diagnosis of cognitive impairment with no dementia), or level 3 (dependence in at least two ADLs, having mobility impairment or having a diagnosis of dementia) [39]. The CSHA Function Scale is based on 12 of 14 OARS ADL and IADL items (walking and transferring items were excluded from ADL). Each item is rated as 0 (without help), 1 (with some help), or 2 (completely unable) [44]. The CSHA Function Scale score is calculated by dividing the sum of each item score by 24 , with a final score range of 0 to 1 (lower score represents better function).

We also examined the association between the FI-CGA10 and several features that are commonly seen in frail older adults such as functional and cognitive impairments, high comorbidity burden, and poor self-rated health (SRH) status. Functional status was assessed using the Timed Up and Go test [45], self-reported ability to walk one block and several blocks (1, limited a lot; 2 , limited a little; 3 , not limited at all) [46], and independent life-space (LS-I; the highest life-space level attained without help from a person and without using any equipment) and life-space using equipment (LS-E; the highest life-space level attained without help from a person, even if equipment was used). LS-I and LS-E levels range from within one's dwelling (level 0) to beyond one's town (level 5) [47]. Cognitive status was represented by the Mini-Cog score. As comparator variables, comorbidity burden was assessed by the Charlson 
Table 3. The FI-CGA-10 variables by frailty category

\begin{tabular}{|c|c|c|c|c|}
\hline FI-CGA-10 variables & $\begin{array}{l}\text { All patients } \\
(n=540), n(\%)\end{array}$ & $\begin{array}{l}\text { Fit }(0 \text { to }<0.2) \\
(n=109), n(\%)\end{array}$ & $\begin{array}{l}\text { Pre-Frail }(0.2-0.35) \\
(n=219), n(\%)\end{array}$ & $\begin{array}{l}\text { Frail }(>0.35) \\
(n=212), n(\%)\end{array}$ \\
\hline \multicolumn{5}{|l|}{ 1. Cognition } \\
\hline 0 (no problem) & $269(50)$ & $94(86)$ & $122(56)$ & $53(25)$ \\
\hline 0.5 (minor problem) & $150(28)$ & $15(14)$ & $70(32)$ & $65(31)$ \\
\hline 1.0 (major problem) & $121(22)$ & 0 & $27(12)$ & $94(44)$ \\
\hline \multicolumn{5}{|l|}{ 2. Emotion } \\
\hline 0 (no problem) & $424(79)$ & $101(93)$ & $178(81)$ & $145(68)$ \\
\hline 0.5 (minor problem) & $55(10)$ & $7(6)$ & $28(13)$ & $20(9)$ \\
\hline 1.0 (major problem) & $61(11)$ & $1(1)$ & $13(6)$ & $47(22)$ \\
\hline \multicolumn{5}{|l|}{ 3. Communication } \\
\hline 0 (no problem) & $338(63)$ & $99(91)$ & $146(67)$ & $93(44)$ \\
\hline 0.5 (minor problem) & $136(25)$ & $10(9)$ & $58(26)$ & $68(32)$ \\
\hline 1.0 (major problem) & $66(12)$ & 0 & $15(7)$ & $51(24)$ \\
\hline \multicolumn{5}{|l|}{ 4. Mobility } \\
\hline 0 (no problem) & $109(20)$ & $57(52)$ & $47(21)$ & $5(2)$ \\
\hline 0.5 (minor problem) & $217(40)$ & $47(43)$ & $127(58)$ & $43(20)$ \\
\hline 1.0 (major problem) & $214(40)$ & $5(5)$ & $45(21)$ & $164(77)$ \\
\hline \multicolumn{5}{|l|}{ 5. Balance } \\
\hline 0 (no problem) & $437(81)$ & $107(98)$ & $196(90)$ & $134(63)$ \\
\hline 0.5 (minor problem) & $65(12)$ & $2(2)$ & $21(10)$ & $42(20)$ \\
\hline 1.0 (major problem) & $38(7)$ & 0 & $2(1)$ & $36(17)$ \\
\hline \multicolumn{5}{|l|}{ 6. Nutrition } \\
\hline 0 (no problem) & $352(65)$ & $97(89)$ & $141(64)$ & $114(54)$ \\
\hline 0.5 (minor problem) & $126(23)$ & $11(10)$ & $62(28)$ & $53(25)$ \\
\hline 1.0 (major problem) & $62(11)$ & $1(1)$ & $16(7)$ & $45(21)$ \\
\hline \multicolumn{5}{|l|}{ 7. ADL } \\
\hline 0 (no problem) & $368(68)$ & $102(94)$ & $188(86)$ & 78 (37) \\
\hline 0.5 (minor problem) & $60(11)$ & $7(6)$ & $28(13)$ & $25(12)$ \\
\hline 1.0 (major problem) & $112(21)$ & 0 & $3(1)$ & $109(51)$ \\
\hline \multicolumn{5}{|l|}{ 8. IADL } \\
\hline 0 (no problem) & $235(44)$ & $105(96)$ & $121(55)$ & $9(4)$ \\
\hline 0.5 (minor problem) & $114(21)$ & $4(4)$ & $72(33)$ & $38(18)$ \\
\hline 1.0 (major problem) & $191(35)$ & 0 & $26(12)$ & $165(78)$ \\
\hline \multicolumn{5}{|l|}{ 9. Social support } \\
\hline 0 (no problem) & $216(40)$ & $59(54)$ & $82(37)$ & $75(35)$ \\
\hline 0.5 (minor problem) & $270(50)$ & $50(46)$ & $113(52)$ & $107(50)$ \\
\hline 1.0 (major problem) & $54(10)$ & 0 & $24(11)$ & $30(14)$ \\
\hline \multicolumn{5}{|l|}{ 10. Comorbidity } \\
\hline 0 (no problem) & $88(16)$ & $42(39)$ & $36(16)$ & $10(5)$ \\
\hline 0.5 (minor problem) & $295(55)$ & $62(57)$ & $134(61)$ & $99(47)$ \\
\hline 1.0 (major problem) & $157(29)$ & $5(5)$ & $49(22)$ & $103(49)$ \\
\hline
\end{tabular}

Abbreviation: ADL, activities of daily living; FI-CGA-10, 10-item frailty index based on a comprehensive geriatric assessment; IADL, instrumental activities of daily living.

comorbidity index and a number of medications [48]. SRH status was evaluated using a validated single question, "In general, would you say your health is excellent (1), very good (2), good (3), fair (4), or poor (5)?" [49].

As an alternative to assessing the ability of the FICGA-10 to predict mortality, we tested the correlation between the FI-CGA-10 and validated prognostic indices for mortality, such as the Lee index and the Schonberg index [50-53]. The Lee index ranges from 0 to 23 based on 12 weighted items, and the Schonberg index ranges from 0 to 29 based on 11 weighted items. Higher scores reflect a higher risk of mortality within 4 and 10 years 
(Lee index) or within 5, 10, and 14 years (Schonberg index).

Lastly, we explored the association between the FI-CGA10 and the ECOG PS, which is a functional status measure widely used by oncologists [54]. The ECOG PS classifies patients based on their physical ability, daily activity, and self-care ability, ranging from 0 (fully active) to 4 (completely disabled).

\section{Statistical Analysis}

Descriptive analyses were performed to summarize sample characteristics. We assessed the fit of the distribution of the observed FI-CGA-10 using a gamma density function. This is a positively skewed distribution with a long right tail that has been observed with the FIs and the original FI-CGA $[6,9,55]$. Correlation analyses were performed using Pearson's correlation. A chi-square test or one-way analysis of variance was used to assess bivariable associations between the frailty categories and frailty characteristics for categorical and continuous variables, respectively. For a more detailed categorization of patient fitness and frailty level, we mapped the FI-CGA-10 to the CFS by calculating descriptive statistics of the FI-CGA-10 scores according to the seven CFS categories. A value of $p<.05$ was considered statistically significant for all analyses. Analyses were performed using Stata 16 software (StataCorp LLC, College Station, TX), an R package ("fitdistrplus"), and BoxPlotR [56].

\section{RESUlTS}

\section{Patient Characteristics}

Five hundred and fifty-nine patients underwent CGA at the geriatric oncology service between September 2018 and October 2020. Later, five patients were found to have a noncancer diagnosis and excluded from the final cohort. For 14 patients who had the CGA done twice at different time points during their cancer treatment, only their initial CGA results were included. The final study population consisted of 540 patients. We did not set any referral criteria for a CGA based on age or G8 score, and 46 patients aged 65-74 years who had not been screened by the $G 8$ were referred. The median age was 80 years (range, 6696 years), and $61 \%$ were male. Most of the patients had ECOG performance scores of 0 or 1 (75\%) with a range of $0-4$. The most common type of cancer was gastrointestinal tract $(37 \%)$. Detailed patient characteristics are shown in Table 2.

\section{Characteristics of the FI-CGA-10}

The mean \pm SD of the FI-CGA-10 was $0.34 \pm 0.18$, and the distribution of scores is shown in Figure 1. By visual inspection of Figure 1, the skewed distribution was well approximated by the gamma distribution parameters of shape (2.64) and scale (0.13). The number of patients with each scoring variable in the FI-CGA-10 is presented in Table 3.

\section{Construct Validity of the FI-CGA-10}

Using the FI-CGA-10, $20 \%$ of patients ( $n=109$ ) were categorized as fit, $41 \%(n=219)$ as pre-frail, and $39 \%(n=212)$ as frail. Patients with higher scores on the FI-CGA-10 had higher scores on previously validated frailty measures (Table 4). The FI-CGA-10 correlated with the CFS (Pearson's $r=0.83 ; 95 \% \mathrm{Cl}, 0.80-0.85$; supplemental online Fig. 1), CSHA rules-based frailty definition $(r=0.67 ; 95 \% \mathrm{Cl}, 0.62-$ 0.72 ), and CSHA Function Score ( $r=0.77 ; 95 \% \mathrm{Cl}, 0.74-$ 0.81). Table 4 summarizes the clinical characteristics by grade of frailty. As expected, the distribution of the frailty indicators differed significantly between each level of frailty. Table 4 also shows prognostic indices by FI-CGA-10-based frailty category. People who were frailer had higher scores on the Lee index and the Schonberg index, suggesting an increased probability of death. The high degree of correlation between the FI-CGA-10 and established frailty measures supports construct validity.

\section{Six Levels of Fitness and Frailty}

FI-CGA-10 scores mapped to the seven CFS categories are shown in supplemental online Table 1 and in Figure 2. The number of patients categorized as CFS 1 (very fit, $n=7$ ) and CFS 2 (well, $n=11$ ) were small and were collapsed into one category. Based on the distribution of the FI-CGA-10 by the CFS, we divided the FI-CGA-10 scores into six levels of fitness and frailty. FI-CGA-10 level 1 has a score of $\leq 0.1$, corresponding to the CFS very fit and well categories; level 2 has a score of $0.15-0.20$ (managing well); level 3 has a score of $0.25-0.30$ (vulnerable); level 4 has a score of $0.35-$ 0.45 (mildly frail); level 5 has a score of $0.50-0.60$ (moderately frail); and level 6 has a score of $\geq 0.65$ (severely frail). According to this six-level classification, greater frailty was associated with higher scores for both comparator frailty measures: the CSHA rules-based frailty definition $(r=0.67)$ and the CSHA Function Score $(r=0.73)$. Similar associations were found for the prognostic indices: Lee index $(r=0.64)$ and Schonberg index $(r=0.54)$. Increasing levels of frailty were associated with worse functional and cognitive status, higher comorbidity burden, and worse SRH in a doseresponse manner (supplemental online Table 2).

\section{Discussion}

In this cohort of older adults with cancer, we constructed an FI-CGA-10 by modifying the FI-CGA developed initially in the general geriatric setting. The FI-CGA was designed to measure the well-described concept of frailty in older people [57]. This new FI-CGA-10 evaluated the same CGA domains as the original FI-CGA, including cognition, mood, communication (hearing and vision), mobility, balance, nutrition, daily activities (including bladder or bowel incontinence), social support, and comorbidity [8, 9]. These domains cover the four cardinal components of CGAphysical health, functional status, psychological health, and socioenvironmental factors [12-14]. Furthermore, almost all of the individual domains of the FI-CGA-10 were associated with adverse outcomes in older adults with cancer $[58,59]$. The comprehensiveness of this coverage of CGA domains supports the content validity of our new scale.

The calculation of an FI-CGA-10 score is much more straightforward than for an FI-CGA score. The original $\mathrm{FI}-$ CGA comprises of an impairment index (range 0-10) and a 
Table 4. Comparator frailty measures, frailty characteristics, and prognostic indices by the three frailty categories

\begin{tabular}{|c|c|c|c|}
\hline Measures & $\begin{array}{l}\text { Fit }(0 \text { to } \\
<0.2)(n=109)\end{array}$ & $\begin{array}{l}\text { Pre-Frail }(0.2- \\
0.35)(n=219)\end{array}$ & $\begin{array}{l}\text { Frail } \\
(>0.35)(n=212)\end{array}$ \\
\hline \multicolumn{4}{|l|}{ Comparator frailty measure, mean (SD) ${ }^{a}$} \\
\hline CSHA Clinical Frailty Scale (range 1-7) & $3.17(0.87)$ & $4.22(0.64)$ & $5.60(0.88)$ \\
\hline CSHA rules-based frailty definition (range $0-3$ ) & $0.36(0.71)$ & $1.14(1.12)$ & $2.40(0.87)$ \\
\hline CSHA Function Score (range 0-1) & $0.01(0.02)$ & $0.05(0.07)$ & $0.31(0.21)$ \\
\hline \multicolumn{4}{|l|}{ Frailty Characteristic } \\
\hline Timed Up and Go test (seconds), mean (SD) ${ }^{a}$ & $11.26(1.82)$ & $13.02(3.11)$ & $26.34(20.37)$ \\
\hline \multicolumn{4}{|l|}{ Self-reported ability to walk one block, $n(\%)^{a}$} \\
\hline Not limited at all & $105(96)$ & $189(86)$ & $78(37)$ \\
\hline Limited a little & $4(4)$ & $23(11)$ & $51(24)$ \\
\hline Limited a lot & $0(0)$ & $7(3)$ & $83(39)$ \\
\hline \multicolumn{4}{|l|}{ Self-reported ability to walk several blocks, $n(\%)^{\mathrm{a}}$} \\
\hline Not limited at all & $90(83)$ & $124(57)$ & $30(14)$ \\
\hline Limited a little & $15(14)$ & $67(31)$ & $55(26)$ \\
\hline Limited a lot & $4(4)$ & $28(13)$ & $127(60)$ \\
\hline Independent life-space (range 0-5), mean (SD) ${ }^{a}$ & $4.86(0.69)$ & $4.34(1.22)$ & $2.07(1.73)$ \\
\hline Life-space using equipment (range $0-5$ ), mean (SD) ${ }^{a}$ & $4.93(0.5)$ & $4.62(0.76)$ & $2.60(1.56)$ \\
\hline Mini-Cog (range 0-5), mean (SD) & $4.71(0.66)$ & $4.04(1.27)$ & $3.10(1.66)$ \\
\hline Charlson comorbidity index (range $0-37$ ), mean (SD) ${ }^{a}$ & $0.79(1.27)$ & $1.38(1.54)$ & $1.92(1.87)$ \\
\hline No. of medications, mean (SD) ${ }^{a}$ & $4.34(3.38)$ & $5.27(3.28)$ & $6.39(3.48)$ \\
\hline \multicolumn{4}{|l|}{ Self-rated health status, $n(\%)^{\mathrm{a}}$} \\
\hline Excellent/very good & $28(26)$ & $31(14)$ & $6(3)$ \\
\hline Good & $39(36)$ & $63(29)$ & $41(19)$ \\
\hline Fair & $26(24)$ & $74(34)$ & $52(25)$ \\
\hline Poor & $16(15)$ & $51(23)$ & $113(53)$ \\
\hline \multicolumn{4}{|l|}{ Prognostic indices for mortality, mean (SD) ${ }^{a}$} \\
\hline Lee index (range 0-23) & $7.33(1.92)$ & $8.77(2.36)$ & $12.00(3.11)$ \\
\hline Schonberg index (range 0-29) & $10.14(2.93)$ & $13.08(3.81)$ & $15.70(3.47)$ \\
\hline \multicolumn{4}{|l|}{ Oncology performance status measure } \\
\hline ECOG PS, mean (SD) ${ }^{a}$ & $0.37(0.50)$ & $0.64(0.59)$ & $1.81(0.95)$ \\
\hline \multicolumn{4}{|l|}{ ECOG PS, $n(\%)^{a}$} \\
\hline Score 0 & $70(64)$ & $91(42)$ & $9(4)$ \\
\hline Score 1 & $38(35)$ & $117(53)$ & $81(38)$ \\
\hline Score 2 & $1(1)$ & $10(5)$ & $73(34)$ \\
\hline Score 3-4 & 0 & $1(0.5)$ & $49(23)$ \\
\hline
\end{tabular}

${ }^{b}$ Patients unable to perform the Timed Up and Go test were included using a surrogate time that was the slowest time of this cohort of patients.

Abbreviations: CSHA, Canadian Study of Health and Aging; ECOG PS, Eastern Cooperative Oncology Group performance status.

comorbidity index (range 0-4) [9]. To calculate the FI-CGA score, the sum of the impairment and comorbidity index scores is divided by 14 . By contrast, the FI-CGA-10 consists of 10 domains, with the score calculated by dividing the sum of the scores for each domain by 10 . Along with the simple rating system for each domain (no [0 points], minor [0.5 points], or a major problem [1 point]), it is feasible to calculate an FICGA-10 score with just pencil and paper.

Even after these modifications, the FI-CGA-10 maintained the mathematical properties of the Fls and the original FI-CGA $[6,9,55]$. For example, the FI-CGA-10 had an asymmetrical distribution that was well represented by the gamma density function. According to Rockwood and Mitnitski, an optimal frailty index should contain at least 30 items, but the lowest practical limit was suggested to be about 10 to 15 items $[60,61]$. They pointed out that carefully selecting the items to be included in the index becomes increasingly important when an index includes fewer items. Notably, the FI-CGA-10 developed following these instructions demonstrated good construct validity and included data for all the domains evaluated in the CGA. Our scale correlated with established frailty measurement tools and health characteristics that are commonly 


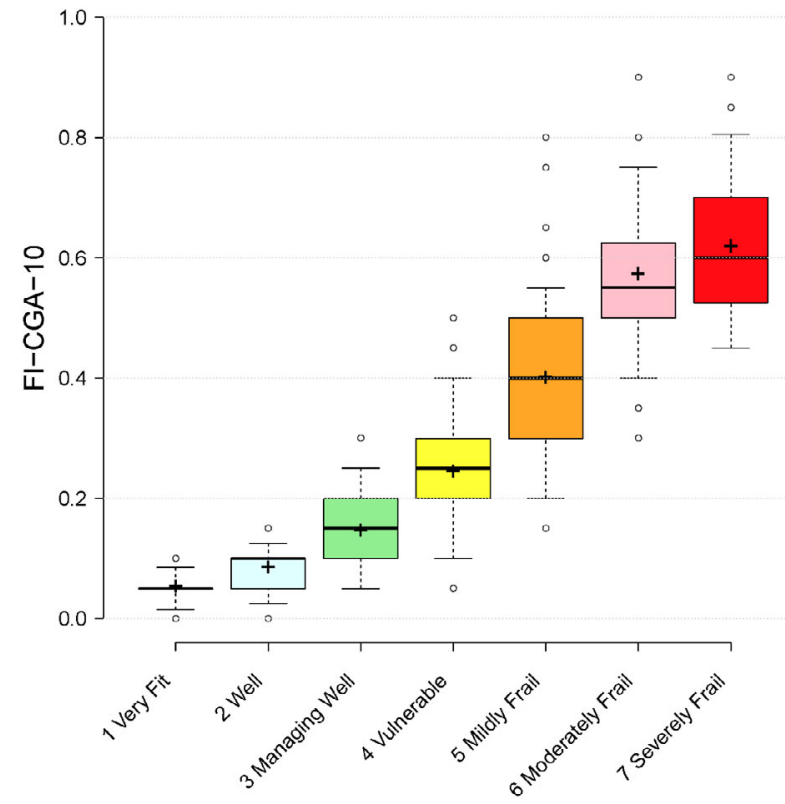

Figure 2. A box plot to illustrate the distribution of the FI-CGA10 scores by the Clinical Frailty Scale. Center lines show the medians; box limits indicate the 25th and 75th percentiles; whiskers extend to 5th and 95th percentiles, outliers are represented by dots; crosses represent sample means. $n=7(1$, very fit), 11 ( 2 , well), 70 (3, managing well), 189 (4, vulnerable), 153 (5, mildly frail), 71 (6, moderately frail), 39 (7, severely frail) sample points. Abbreviation: FI-CGA-10, 10-item frailty index based on a comprehensive geriatric assessment

observed in frail older people, such as functional impairments. Furthermore, we classified patients into different fitness and frailty degrees, which made the FI-CGA-10 score more clinically interpretable. We proposed six levels of fitness and frailty in addition to the previously reported three categories (fit, pre-frail, and frail) $[33,34]$. This more granular categorization may permit a more precise selection of oncologic treatment for individual patients as it correlates with patient function. According to the intensity of treatment, different levels of physiologic reserve and resilience to stressors are desired. The information from our objective measure has the potential to aid the physician, patient, and family in shared decisionmaking.

There are limitations to our study. First, the present study was conducted at a single Japanese academic cancer center (NKCC) and all included patients were referred for CGA at the discretion of their treating physicians. These factors may limit the generalizability of our findings to the overall population of older adults with cancer. Second, we could not evaluate the criterion validity of the FICGA-10. Criterion validation is usually divided into two types: concurrent validation and predictive validation [62]. Because there is no "gold standard" measure of frailty to test concurrent validity, another form of criterion validation, predictive validation, has been assessed for frailty measures. For the original FI-CGA, the predictive ability for adverse outcomes was evaluated [8, 9]. Jones et al. showed that a higher FI-CGA score was associated with a higher risk of institutionalization and death in the CSHA-2 cohort [9]. The FI-CGA correlated well with the $\mathrm{FI}(r=0.76)$, and the predictive performance of the FI-CGA was comparable to that of the FI. The area under the receiver operating characteristic curve (AUC) for predicting 5-year mortality was 0.67 and 0.70 , respectively, for the FI-CGA and the FI. Additionally, Pilotto et al. reported that the FI-CGA and the FI had similar AUCs for 1 -year mortality (0.727 vs. 0.729$)$ in a prospective cohort study of hospitalized older patients [63].

Recently, several Fls with more than 30 variables were developed, and their predictive validity was studied in the field of geriatric oncology [33, 34, 64]. Guerard et al. constructed the 36-item Carolina Frailty Index (CFI) from the Carolina Senior Registry (NCT01137825), an institutional database of patients with cancer 65 years or older who completed a cancer-specific geriatric assessment [33]. CFI scores were categorized as robust $(0$ to $<0.2)$, pre-frail (0.2-0.35), and frail (>0.35). In a sample of 546 patients, the 5 -year survival probability was $72 \%$ in robust patients, $58 \%$ in pre-frail patients, and $34 \%$ in frail patients (logrank test, $p<.0001$ ). Because of the limited follow-up duration in the present study, we could not determine the predictive validity of the FI-CGA-10. As indirect evidence, the FI-CGA-10 highly correlated to the prognostic indices for mortality, which have been extensively validated in general geriatric populations and also studied in older adults with breast cancer [50-53, 65]. With more mature survival data, we plan to test how well our index correlates with mortality and the validity of the cutoff values defining each level of frailty.

The strength of the FI-CGA-10 compared with other FIs is that it gives a better summary of what constitutes a certain level of fitness and frailty. This comes from the fact that the FI-CGA-10 counts domain-level deficits and other FIs count item-level deficits. By calculating a FI-CGA-10 score, it becomes clear where vulnerabilities exist in a patient and how severe they are. This information is fundamental to holistic understanding of the patient's overall health status and to performing multidimensional and interdisciplinary interventions based on the identified vulnerabilities, which is the purpose of CGA. If the predictive validity of the FICGA-10 is established, it could be a more clinically meaningful and actionable scale.

\section{Conclusion}

We developed the FI-CGA-10 by simplifying the original FI-CGA while maintaining its content validity. We demonstrated the construct validity of our index in a cohort of older adults with various cancer types. The advantage of the FI-CGA-10 is that a score can be calculated more readily and interpreted in a more clinically sensible manner than the original FI-CGA and other FIs. In addition to grading the level of frailty, this tool can improve a patient's health status by pointing to the need for tailored interventions to address the identified vulnerabilities. If the predictive validity and external validity are demonstrated, the FI-CGA-10 will be a useful CGA-based frailty measure in the geriatric oncology setting. 


\section{Acknowledgments}

The authors would like to thank Kirsten A. Nyrop for her expertise and help in reviewing and revising the manuscript. This work was supported by the Fukuoka Foundation for Sound Health Cancer Research Fund (2019, to T.F.N.), a grant from the Clinical Research Promotion Foundation (2019, to T.F.N.), and JSPS KAKENHI grant 20K16540 (to T.F.N.).
Provision of study material or patients: Tomohiro F. Nishijima, Masaru Morita

Collection and/or assembly of data: Tomohiro F. Nishijima, Masaru Morita

Data analysis and interpretation: Tomohiro F. Nishijima, Mototsugu Shimokawa, Taito Esaki, Masaru Morita, Yasushi Toh, Hyman B. Muss

Manuscript writing: Tomohiro F. Nishijima, Mototsugu Shimokawa, Taito Esaki, Masaru Morita, Yasushi Toh, Hyman B. Muss

Final approval of manuscript: Tomohiro F. Nishijima, Mototsugu Shimokawa, Taito Esaki, Masaru Morita, Yasushi Toh, Hyman B. Muss
Author Contributions

Conception/design: Tomohiro F. Nishijima, Mototsugu Shimokawa, Yasushi Toh, Hyman B. Muss

\section{Disclosures}

The authors indicated no financial relationships.

\section{REFERENCES}

1. Morley JE, Vellas B, van Kan GA et al. Frailty consensus: A call to action. J Am Med Dir Assoc 2013;14:392-397.

2. Handforth $C$, Clegg $A$, Young $C$ et al. The prevalence and outcomes of frailty in older cancer patients: A systematic review. Ann Oncol 2015;26:1091-1101.

3. Ethun CG, Bilen MA, Jani $A B$ et al. Frailty and cancer: Implications for oncology surgery, medical oncology, and radiation oncology. CA Cancer J Clin 2017;67:362-377.

4. Clegg A, Young J, lliffe $S$ et al. Frailty in elderly people. Lancet 2013;381:752-762.

5. Fried LP, Tangen CM, Walston J et al. Frailty in older adults: Evidence for a phenotype. J Gerontol A Biol Sci Med Sci 2001;56:M146M156.

6. Mitnitski AB, Mogilner AJ, Rockwood K. Accu mulation of deficits as a proxy measure of aging ScientificWorldJournal 2001;1:323-336.

7. Sutton JL, Gould RL, Daley S et al. Psychometric properties of multicomponent tools designed to assess frailty in older adults: A systematic review. BMC Geriatr 2016;16:55.

8. Jones DM, Song $X$, Rockwood $K$ Operationalizing a frailty index from a standardized comprehensive geriatric assessment. J Am Geriatr Soc 2004;52:1929-1933.

9. Jones D, Song X, Mitnitski A, Rockwood K Evaluation of a frailty index based on a comprehensive geriatric assessment in a population based study of elderly Canadians. Aging Clin Exp Res 2005;17:465-471.

10. Rockwood K, Silvius JL, Fox RA. Comprehensive geriatric assessment. Helping your elderly patients maintain functional well-being. Postgrad Med 1998;103:247-249, 254-248, 264.

11. Bellera CA, Rainfray $M$, MathoulinPelissier $\mathrm{S}$ et al. Screening older cancer patients First evaluation of the G-8 geriatric screening tool. Ann Oncol 2012;23:2166-2172.

12. Rubenstein LZ. Joseph T. Freeman Award Lecture: Comprehensive geriatric assessment From miracle to reality. J Gerontol A Biol Sci Med Sci 2004;59:473-477.

13. Puts MTE, Alibhai SMH. Fighting back against the dilution of the Comprehensive Geriatric Assessment. J Geriatr Oncol 2018;9:3-5.

14. Klepin HD, Wildes TM. Fighting for the integration of geriatric principles into oncology. J Geriatr Oncol 2018;9:705-706.

15. Zubrod CG, Schneiderman M, Frei III E et al. Appraisal of methods for the study of chemotherapy of cancer in man: Comparative therapeutic trial of nitrogen mustard and triethylene thiophosphoramide. J Chron Dis 1960; 11:7-33.

16. Conwell Y, Forbes NT, Cox C, Caine ED. Validation of a measure of physical illness burden at autopsy: The Cumulative Illness Rating Scale. J Am Geriatr Soc 1993;41:38-41.

17. Borson S, Scanlan J, Brush $M$ et al. The mini-cog: A cognitive 'vital signs' measure for dementia screening in multi-lingual elderly. Int J Geriatr Psychiatry 2000;15:1021-1027.

18. Nasreddine ZS, Phillips NA, Bedirian V et al The Montreal Cognitive Assessment, MoCA: A brief screening tool for mild cognitive impairment. J Am Geriatr Soc 2005;53:695-699.

19. McCarten JR, Anderson $P$, Kuskowski MA et al. Finding dementia in primary care: The results of a clinical demonstration project. J Am Geriatr Soc 2012;60:210-217.

20. Folstein MF, Folstein SE, McHugh PR. "Minimental state". A practical method for grading the cognitive state of patients for the clinician. J Psychiatr Res 1975;12:189-198.

21. Li C, Friedman B, Conwell Y, Fiscella K. Valid ity of the Patient Health Questionnaire 2 (PHQ-2) in identifying major depression in older people. J Am Geriatr Soc 2007;55:596-602.

22. Kroenke K, Spitzer RL, Williams JB. The PHQ-9: Validity of a brief depression severity measure. J Gen Intern Med 2001;16:606-613.

23. Hurria A, Gupta S, Zauderer M et al. Developing a cancer-specific geriatric assessment: A feasibility study. Cancer 2005;104:1998-2005.

24. Fillenbaum GG. Multidimensional Functional Assessment of Older Adults: The Duke Older Americans Resources and Services Procedures. New York: Psychology Press, 2013.

25. Studenski S, Perera $S$, Patel $K$ et al. Gait speed and survival in older adults. JAMA 2011; 305:50-58.

26. Puts MT, Monette J, Girre V et al. The fal rate of older community-dwelling cancer patients. Support Care Cancer 2013;21:775-783.

27. Elia M; Malnutrition Advisory Group of the British Association for Parenteral and Enteral Nutrition (BAPEN). The 'MUST' Report. Nutritional Screening for Adults: A Multidisciplinary Responsibility. Development and Use of the 'Malnutrition Universal Screening Tool' ('MUST') for Adults. Redditch, U.K.: BAPEN, 2003.

28. Droz JP, Balducci L, Bolla $M$ et al. Management of prostate cancer in older men
Recommendations of a working group of the International Society of Geriatric Oncology. BJU Int 2010;106:462-469.

29. Fillenbaum GG, Smyer MA. The development, validity, and reliability of the OARS multidimensional functional assessment questionnaire. J Gerontol 1981:36:428-434.

30. Sherbourne CD, Stewart AL. The MOS social support survey. Soc Sci Med 1991;32:705-714.

31. Miller MD, Paradis CF, Houck PR et al. Rating chronic medical illness burden in geropsychiatric practice and research: Application of the Cumulative Illness Rating Scale. Psychiatry Res 1992;41:237-248.

32. Salvi F, Miller MD, Grilli A et al. A manual of guidelines to score the modified cumulative illness rating scale and its validation in acute hospitalized elderly patients. J Am Geriatr Soc 2008; 56:1926-1931.

33. Guerard EJ, Deal AM, Chang $Y$ et al. Frailty index developed from a cancer-specific geriatric assessment and the association with mortality among older adults with cancer. J Natl Compr Canc Netw 2017;15:894-902.

34. Cohen HJ, Smith $D$, Sun $C L$ et al. Frailty as determined by a comprehensive geriatric assessment-derived deficit-accumulation index in older patients with cancer who receive chemotherapy. Cancer 2016;122:3865-3872.

35. Dodson JA, Hajduk AM, Geda $M$ et al. Predicting 6-month mortality for older adults hospitalized with acute myocardial infarction: A cohort study. Ann Intern Med 2020;172:12-21.

36. Hayman KJ, Kerse N, Dyall L et al. Life and living in advanced age: A cohort study in New Zealand - Te Puāwaitanga o Nga Tapuwae Kia Ora Tonu, LiLACS NZ: Study protocol. BMC Geriatr 2012;12:33.

37. Brefka $S$, Dallmeier D, Muhlbauer $V$ et al. A proposal for the retrospective identification and categorization of older people with functional impairments in scientific studies-recommendations of the Medication and Quality of Life in Frail Older Persons (MedQoL) Research Group. J Am Med Dir Assoc 2019;20:138-146.

38. Sylliaas $H$, Idland $G$, Sandvik $L$ et al. Does mortality of the aged increase with the number of falls? Results from a nine-year follow-up study. Eur J Epidemiol 2009;24:351-355

39. Rockwood K, Stadnyk K, MacKnight $C$ et al. A brief clinical instrument to classify frailty in elderly people. Lancet 1999;353:205-206.

40. Jolly TA, Deal AM, Nyrop KA et al. Geriatric assessment-identified deficits in older cancer 
patients with normal performance status. The Oncologist 2015;20:379-385.

41. Manokumar T, Aziz S, Breunis $\mathrm{H}$ et al. A prospective study examining elder-relevant outcomes in older adults with prostate cancer undergoing treatment with chemotherapy or abiraterone. J Geriatr Oncol 2016;7:81-89.

42. Rolfson DB, Majumdar SR, Tsuyuki RT et al. Validity and reliability of the Edmonton Frail Scale. Age Ageing 2006;35:526-529.

43. Pilotto A, Ferrucci L, Franceschi $M$ et al. Development and validation of a multidimensional prognostic index for one-year mortality from comprehensive geriatric assessment in hospitalized older patients. Rejuvenation Res 2008;11:151-161.

44. Rockwood K, Song X, MacKnight $C$ et al. A global clinical measure of fitness and frailty in elderly people. CMAJ 2005;173:489-495.

45. Podsiadlo D, Richardson S. The timed "Up \& Go": A test of basic functional mobility for frail elderly persons. J Am Geriatr Soc 1991;39:142-148.

46. Stewart AL, Ware JE. Measuring Functioning and Well-Being: The Medical Outcomes Study Approach. Durham, NC: Duke University Press, 1992.

47. Baker PS, Bodner EV, Allman RM. Measuring life-space mobility in community-dwelling older adults. J Am Geriatr Soc 2003;51:1610-1614.

48. Charlson ME, Pompei $\mathrm{P}$, Ales $\mathrm{KL}$, Mackenzie CR. A new method of classifying prognostic comorbidity in longitudinal studies: Development and validation. J Chronic Dis 1987;40 373-383.
49. Meurer LN, Layde PM, Guse CE. Self-rated health status: A new vital sign for primary care? WMJ 2001;100:35-39.

50. Lee SJ, Lindquist K, Segal MR, Covinsky KE. Development and validation of a prognostic index for 4-year mortality in older adults. JAMA 2006;295:801-808.

51. Cruz M, Covinsky K, Widera EW et al. Predicting 10-year mortality for older adults. JAMA 2013;309:874-876.

52. Schonberg MA, Davis RB, McCarthy EP, Marcantonio ER. Index to predict 5-year mortality of community-dwelling adults aged 65 and older using data from the National Health Interview Survey. J Gen Intern Med 2009;24:11151122

53. Schonberg MA, Li V, Marcantonio ER et al. Predicting mortality up to 14 years among community-dwelling adults aged 65 and older. J Am Geriatr Soc 2017;65:1310-1315

54. Oken MM, Creech RH, Tormey DC et al. Tox icity and response criteria of the Eastern Cooperative Oncology Group. Am J Clin Oncol 1982;5: 649-655.

55. Searle SD, Mitnitski A, Gahbauer EA et al. A standard procedure for creating a frailty index. BMC Geriatr 2008;8:24.

56. Spitzer M, Wildenhain J, Rappsilber J, Tyers M. BoxPlotR: A web tool for generation of box plots. Nat Methods 2014;11:121-122.

57. Rockwood K, Fox RA, Stolee $P$ et al. Frailty in elderly people: An evolving concept. CMAJ 1994;150:489-495.

58. Bruijnen $C P$, van Harten-Krouwel DG, Koldenhof JJ et al. Predictive value of each geriatric assessment domain for older patients with cancer: A systematic review. J Geriatr Oncol 2019;10:859-873.

59. Sarfati D, Koczwara B, Jackson C. The impact of comorbidity on cancer and its treatment. CA Cancer J Clin 2016;66:337-350.

60. Fillit HM, Rockwood K, Young JB. Brocklehurst's Textbook of Geriatric Medicine and Gerontology. 8th ed. New York: Elsevier Health Sciences, 2016.

61. Rockwood K, Andrew M, Mitnitski A. A comparison of two approaches to measuring frailty in elderly people. J Gerontol A Biol Sci Med Sci 2007;62:738-743.

62. Streiner DL, Norman GR, Cairney J. Health Measurement Scales: A Practical Guide to Their Development and Use. New York: Oxford University Press, 2015.

63. Pilotto A, Rengo F, Marchionni $\mathrm{N}$ et al. Comparing the prognostic accuracy for all-cause mortality of frailty instruments: A multicentre 1-year follow-up in hospitalized older patients. PLoS One 2012;7:e29090.

64. McCarthy AL, Peel NM, Gillespie KM et al. Validation of a frailty index in older cancer patients with solid tumours. BMC Cancer 2018; 18:892.

65. Kimmick GG, Major B, Clapp J et al. Using ePrognosis to estimate 2-year all-cause mortality in older women with breast cancer: Cancer and Leukemia Group B (CALGB) 49907 and 369901 (Alliance A151503). Breast Cancer Res Treat 2017;163:391-398.

\section{See http://www.TheOncologist.com for supplemental material available online.}

